\section{Sudden unexpected sneezing during the insertion of peribulbar block under propofol sedation}

David C. Abramson MBChB FFA(SA)
The author presents a case report where, following propofol sedation for a peribulbar block, sneezing was induced once the local anaesthetic needle was placed in the orbital cavity. The physiology of sneezing is discussed, as well as the pathophysiology of the ACHOO (Autosomal Dominant Compelling Helio-Ophthalmic Outburst) syndrome, an autosomal dominant condition, present in approximately $25 \%$ of the population, where sneezing is provoked upon expasure to bright light. It is suggested that the anaesthesia induced by propofol may have sensitized patients with this condition to sneeze, since there appeared to be no other excitatory sequelae which have previously been described with propofol.

Cette observation décrit un épisode déternuements survenu pendant une sédation au propofol exécutée pour un bloc péribulbaire. Les étermuements surviennent lorsque l'aiguille pénètre la cavité orbitale. La physiologie de léternuement est discutée ainsi que la physiopathologie du syndrome d'accès d'éternuements provoqués par la lumière intense, affection autosome dominante, présente dans $25 \%$ de la population. On suggère que lanesthésie induite au propofol pourrait provoquer des éternuements chez les patients souffrants de cette condition bien quil ne semble pas que le propofol ail tendance à provoquer de l'excitation.

\section{Key words}

ANAESTHETICS, INTRAVENOUS: propofol;

ANAESTHETIC TECHNIQUES: regional, peribulbar block; COMPLICATIONS: sneezing.

From the Department of Anesthesiology, University of Texas Houston, Health Science Center.

Address correspondence to: Dr. D.C. Abramson,

Department of Anesthesiology, University of Texas, Houston, Health Science Center, 6431 Fannin, MSMB 5.020, Houston, TX 77030.

Accepted for publication 4th April, 1995.
Sneezing during induction of, or during, general anesthesia in humans is not described in the current literature. Previous reports of sneezing have been described with chlormethiazole sedation supplementing spinal anaesthesia, and in an animal model. ${ }^{1,2}$ I wish to report a case where sneezing interferred with the conduct of anaesthesia and could have had a deleterious effect on patient outcome.

A 32-yr-old man presented for corneal transplantation following a chemical burn induced by fertilizer. The same eye had previously been operated upon but with poor results. He was otherwise well. His weight was $70 \mathrm{~kg}$ and height $1.75 \mathrm{~m}$. He denied any history of epileptic events or any drug history. Physical examination was normal and laboratory work revealed a normal haematocrit.

Regional anaesthesia by peribulbar block was planned, administered under light general anaesthesia and utilizing an Atkinson (short bevel) $23 \mathrm{G}$ needle (Visitec ${ }^{\circledR}$, Sarasota, Florida).

A $20 \mathrm{G} \dot{N}$ cannula was secured in the left forearm and the usual monitors (a pulse oximeter, ECG, automatic blood pressure cuff) were placed.

After pre-oxygenation via a Circle Absorber Breathing System for approximately two minutes, anaesthesia was induced with propofol $70 \mathrm{mg} i v\left(1 \mathrm{mg} \cdot \mathrm{kg}^{-1}\right)$ and, as soon as consciousness was lost as evidenced by loss of the eyelid reflex, the first of two peribulbar injections was made over a period of approximately $20 \mathrm{sec}$. The Atkinson needle was placed perpendicularly through the skin at the junction of the lateral third and medial two thirds of the lower orbital ridge to a depth of $38 \mathrm{~mm}$ After aspiration confirmed non-vascular placement, $5 \mathrm{ml}$ of local anaesthetic solution were injected easily. The solution consisted of a mixture of $4.8 \mathrm{ml}$ bupivacaine $0.75 \%, 4.8 \mathrm{ml}$ lidocaine $2 \%, 0.4 \mathrm{ml}$ sodium bicarbonate $4.2 \%$ and $150 \mathrm{IU}$ hyaluronidase, giving a total volume of $10 \mathrm{ml}$.

The needle was withdrawn and placed just inferomedial to the supraorbital notch and advanced perpendic- 
ularly to a depth of $38 \mathrm{~mm}$. The patient immediately took a deep inspiration and sneezed but the needle was withdrawn in between the inspiration and the explosive expiration. Then, the needle was replaced in the same location in an attempt to complete the block but, again, the patient's sneeze reflex was invoked and, again, the needle was withdrawn. After a third attempt at injection with the same response, additional propofol, approximately $0.7 \mathrm{mg} \cdot \mathrm{kg}^{-1}$ was given $i v$ and after $30 \mathrm{sec}$ the second block was completed with no further sneezing. The patient did not display any other movement, or other evidence of excitement.

Pressure was placed over the eye with a Honan's balloon at $30 \mathrm{mmHg}$ pressure, and the degree of ocular muscle akinesia was checked in the now conscious patient after five minutes. Satisfactory block having been achieved, the patient was taken to the operating room approximately one hour after the block was placed and surgery was completed without incident. There was no further sneezing, or other obvious evidence of excitatory movements, and the patient had no recall of events surrounding the local anaethetic administration.

\section{Discussion}

This is the third patient the author has witnessed presenting with this unusual phenomenon of sneezing on induction of anaesthesia. On review of the other two cases, they, too, were both given propofol alone to induce their lightly anaesthetized state with the same results as described above. These latter patients had also denied epileptic history. The author has not experienced this phenomenon with the use of any other form of "light" anaesthesia/sedation used for the placement of eye blocks, including propofol and alfentanil combined, methohexitone, methohexitone and alfentanil combined, and propofol and midazolam combined.

The technique of peribulbar orbital anaesthesia ${ }^{3-6}$ is popular in our institution, since it is considered safe. ${ }^{4}$ Because we use a relatively blunt needle as an added safety precaution to avoid globe puncture, there is a need for some form of sedation and/or analgesia when placing the block. We also attempt to minimize patient discomfort by warming ${ }^{7}$ and alkalinizing ${ }^{6,8}$ the local anaesthetic solution.

The sneeze, or sternutatory reflex, is a primitive neuromuscular physiological response to irritation inborn in most animals. The afferent arc from the anterior and upper nose leads via the anterior ethmoidal nerve branch of the first division of the trigeminal nerve (ophthalmic, $V_{1}$ ) and from the lower nose and the orbit via the second division of the trigeminal nerve (maxillary, $\mathrm{V}_{\mathrm{II}}$ ). The sneezing centre consists of neurones in the trigeminal nu- cleus and adjacent reticular formation. Fibres relay in the pons and medulla and the efferent pathways are the facial nerves, the spinal nerves to the internal intercostal muscles and probably to the diaphragm. Fibres relay from the medulla to the sphenopalatine ganglion and are distributed to the nasal musosal blood vessels and glands, causing secretions and nasal congestion (which, in turn, may stimulate further sneezing). ${ }^{9-11}$ Other stimuli of the medullary centres are bright light, stimulation of the olfactory nerve and stimulation of the skin of face or nose. ${ }^{12}$

The respiratory centre is also directly stimulated from the pons and medulla where the phrenic nerve activates the inspiratory mechanism (which may also come from the nose and not from vagal fibres). The force of expiration is determined by the Hering-Breuer reflex. ${ }^{13}$

What is less well understood is the photic sneeze which occurs when the individual is exposed to bright light. ${ }^{12,14}$ Everett has several theories to explain this phenomenon. ${ }^{15}$

The first theory, that of "optic-trigeminal summation," suggests that stimulating one cranial nerve $\left(V_{1}\right)$ enhances the irritability of the other $\left(\mathrm{V}_{3}\right)$. Just as persistent photic stimulation leads to photophobia via an afferent optic nerve and efferent trigeminal nerve, a photic sneeze might result if the maxillary nerve $\left(V_{3}\right)$ was stimulated instead of the ophthalmic branch $\left(V_{1}\right)$.

The second theory is that of parasympathetic generalization, defined as coactivation of neighbouring parasympathetic fibres by one stimulus. This neuronal generalization may lead to a "trickling sensation," mediated cortically, leading to sneezing.

A third theory suggests direct trigeminal nerve stimulation and increase of ocular sensitivity to light. This has been shown in cases of nephropathic cystinosis where iridescent, birefringent corneal crystals lead to photophobia and photic sneezing. ${ }^{16}$ This hypothesis is supported by the observation that hair pulling or eyebrow plucking may stimulate the sneezing in sensitive individuals.

The photic sneeze reflex is thought to be of autosomal dominant inheritance, with an incidence of approximately $24 \%$ of the population. ${ }^{14,17-21,23}$ In McCusick's book, it is listed under autosomal dominant conditions as the ACHOO Syndrome (for Autosomal Dominant Compelling Helio-Ophthalmic Outburst Syndrome). ${ }^{18}$

There have been well over 30 case reports of neurological excitatory events since the introduction of propofol into clinical use in 1986, ranging from grand-mal convulsions to athetoid movements. Most of the cases described were in patients with pre-existing epilepsy or patients taking pro-convulsant drugs. ${ }^{24-26}$ The current consensus appears that propofol is unlikely to be impli- 
cated as a cause of convulsions and the neurological manifestations seen probably result from subcortical excitatory effects of induction. ${ }^{26-28}$ Spontaneous movement with induction in children which was diminished by increasing the induction dose from $3 \mathrm{mg} \cdot \mathrm{kg}^{-1}$ to $5 \mathrm{mg} \cdot \mathrm{kg}^{-1}$ have also been described. ${ }^{29}$ Spontaneous movement on induction of anaesthesia is not new, having been described with most intravenous induction agents. ${ }^{30}$ Interestingly, excitatory movements are well described with the use of methohexitone, an agent often advocated in the past for use in placing retrobulbar blocks.

The author suggests that the patient demonstrated a photic sneeze response to local irritation of $V_{1}$. This stimulation may have been caused by the technique employed to place the block (i.e., peribulbar, with more peripheral placement of the relatively large injecting needle) and perhaps would not be demonstrated with the intraconal placement of the injecting needle. The absence of any other movement by the patient would imply absence of any excitatory phenomenon as the result of the small dose of propofol used. While the obvious conclusion is to implicate propofol as a stimulator of this reflex, it may just have been very light anaesthesia allowing this poorly understood primitive brainstem reflex to come to the fore. This consequence is reinforced by the fact that the block was completed once additional propofol was given.

Despite not being able to draw a definite conclusion as to the implicating factors of this phenomenon with its potential hazardous effects, this author has now modified his technique to questioning the patient regarding the photic sneeze reflex; if the response is positive, a different technique is employed to the one described above.

\section{References}

1 Seow LT, Mather LE, Cousins MJ. Failure of iv atropine to abolish nasal irritation caused by chlormethiazole infusion in elderly patients undergoing spinal anaesthesia.

Anaesth Intensive Care 1984; 12: 127-30.

2 Haskins $S C$, Peiffer $R L$ Jr, Stowe CM. A clinical comparison of CT1341, ketamine, and xylazine in cats. Am J Vet Res 1975; 36: 1537-43.

3 Hustead RF, Hamilton RC. Techniques. In: Gills JP, Hustead RF, Sanders DR (Eds.). Ophthalmic Anesthesia.

Thorofare, New Jersey: Slack Inc., 1993: 103-86.

4 Hamilton RC, Gimbel HV, Strunin L. Regional anaesthesia for 12,000 cataract extraction and intraocular lens implantation procedures. Can J Anaesth 1988; 35: 615-23.

5 Davis DB II, Mandel MR. Posterior reibulbar anesthesia: an alternative to retrobulbar anesthesia. J Cataract Refract Surg 1986; 12: 182-4.

6 Zahl K, Jordan A, McGroaty J, Gotta AW. pH-adjusted bupivacaine and hyaluronidase for peribulbar blockade. Anesthesiology 1990; 72: 230-2.
7 Heath PJ, Brownlie GS, Herrick MJ. Latency of brachial plexus block. The effect on onset time of warming local anaesthetic solutions. Anaesthesia 1990; 45: 297-301.

8 Coventry DM, Todd JG. Alkalinisation of bupivacaine for sciatic nerve blockade. Anaesthesia 1989; 44: 467-70.

9 Paparella MM, Shumrick DA. Otolaryngology, 2nd ed, Philadelphia: W.B. Saunders Company, 1980: 307-8.

10 Simpson JA, Fitch $W$. Applied neurophysiology with Particular Reference to Anaesthesia. London: John Wright, 1988: 202-3.

11 Korpẫ J, Tomori J. Progress in Respiration Research, Vol 12. Cough and other Respiratory Reflexes. Basel: $S$.

Karger Publishing, 1979: 22-3.

12 Lewkonia I. An infrequent response to slit-lamp examination. Br J Ophthalmol 1969; 53: 493-5.

13 Ganong WF. Review of Medical Physiology, 16th ed. Norwalk, Connecticut: Appleton and Lange, 1993: 617.

14 Forrester $J M$. Sneezing on exposure to bright light as an inherited response. Hum Hered 1985; 35: 113-4.

15 Everett HC. Sneezing in response to light. Neurology 1964; 14: 483-90.

16 Katz B, Melles RB, Swenson MR, Schneider JA. A photic sneeze reflex in nephropathic cystinosis. Br J Ophthalmol 1990; 74: 706-8.

17 Beckman L, Nordenson I. Individual differences with respect to the sneezing reflex: an inherited physiological trait in man? Hum Hered 1983; 33: 390-1.

18 McKusick VA. Autosomal dominant phenotypes, ACHOO syndrome. In: McKusick VA (Ed.). Mendelian Inheritance in Man, 10th ed. Baltimore: The Johns Hopkins University Press, 1992: 12.

19 Morris HM III. ACHOO syndrome. Prevalence and inheritance. Cleve Clin J Med 1987; 54: 431-3.

20 Collie WR, Pagon RA, Hall JG, Shokeir MHK. ACHOO syndrome (autosomal dominant compelling helioophthalmic outburst syndrome). Birth Defects 1978; 14: 361-3.

21 Whitman $B W$, Packer RJ. The photic sneeze reflex: literature review and discussion. Neurology 1993; 43: 868-71.

22 Bevan JC. Propofol-related convulsions (Editorial). Can J Anaesth 1993; 40: 805-9.

23 Lang DM, Howland WC III. Solar sneeze reflex (Letter). JAMA 1987; 257: 1330-1.

24 Ries CR, Scoates PJ, Puil E. Opisthotonos following propofol: a nonepileptic perspective and treatment strategy. Can J Anaesth 1994; 41: 414-9.

25 Reynolds LM, Koh JL. Prolonged spontaneous movement following emergence from propofol/nitrous oxide anesthesia. Anesth Analg 1993; 76: 192-3.

26 Mäkelä JP, Ivvanainen $M$, Pieninkeroinen IP, Waltimo $O$, Lahdensuu $M$. Seizures associated with propofol anesthesia. Epilepsia 1993; 34: 832-5.

27 Borgeat A, Wilder-Smith OHG, Tassonyi E, Suter PM. 
Propofol and epilepsy: time to clarify (Letter). Anesth Analg 1994; 78: 198-9.

28 Nowack WJ, Jordon $R$. Propofol, seizures and generalized paroxysmal fast activity in the EEG. Clin Electroencephalogr 1994; 25: 110-4.

29 Borgeat A, Wilder-Smith OHG, Despland PA, Ravussin P. Spontaneous excitatory movements during recovery from propofol anesthesia in an infant: EEG evaluation. $\mathrm{Br} \mathbf{J}$ Anaesth 1993; 70: 459-61.

30 Whitman JG. Adverse reactions to i.v. induction agents. Br J Anaesth 1978; 50: 677-87. 